\title{
Social Accountability 8000 standard certification: analysis of worldwide diffusion
}

\begin{abstract}
:
This study analyzes the worldwide diffusion of the Social Accountability 8000 standard certification in sixty-five countries and sixty-six activity sectors from 1999 to 2011 . The logistic curve model is used to assess the current situation on both a global scale and a local scale. Additionally, instability and concentration indices are used to analyze whether the diffusion process developed in a homogeneous manner across countries and economic sectors. The results (i) increase the understanding of SA8000's diffusion, (ii) provide an exploratory descriptive analysis of the current SA8000 diffusion worldwide in both macro and microanalyses compared with other standards and (iii) identify future trends in SA8000 diffusion concluding that currently SA8000 follows a similar pattern than other standards and, in consecuence, a growing trend is expected in next years. These findings suggest some challenges and opportunities. The standard must be more flexible to accommodate the differing perspectives of cultures, increase the dialogue with stakeholders, and include more small companies from developing countries.
\end{abstract}

Keywords (5 to 10): Corporate Social Responsibility, management standard, stakeholder, sustainability, SA8000 standard, worldwide diffusion. 
Social Accountability 8000 standard certification: analysis of worldwide diffusion

\section{Introduction}

Currently, corporate social responsibility (CSR) initiatives are more strenuously adopted worldwide in companies as a response to stakeholder demands (Fuentes-García et al., 2008). These initiatives have increased in number and popularity in recent decades (Ligteringen and Zadek, 2004) and have been called ethical because they provide a moral point of view to justify a common, cross-culturally accepted basis (Gilbert and Rasche, 2007). These initiatives include the United Nations (UN) Global Compact, the Organization for Economic Co-operation and Development's (OECD) directory for multinational enterprises, the Global Reporting Initiative (GRI), Sullivan's Global Principles, Social Accountability 8000 (SA8000), and ISO 26000. These initiatives are voluntary in nature and differ in detail, but all encourage corporate responsibility regarding environmental and social issues (Gilbert et al., 2011).

Nevertheless, although other management standards, such as environmental standards, have been broadly implemented (Marimon et al., 2010; 2011), social standards have only been modestly adopted in comparison with other standards such as ISO9001 or ISO14001 (Franceschini et al., 2004; Marimon et al., 2006; Marimon et al., 2010; Llach et al., 2011; Delmas and Montes-Sancho, 2011; Marimon et al., 2012). These initiatives have been classified into four categories (see Gilber et al., 2011; Rache 2012; Brunsson et al., 2012): 1) Standards are standards referred to as general principles for sustainable behavior, UN Global Compact or the OECD Guidelines; 2) Certification standards as SA8000; 3) Reporting standards that provide a framework for sustainable reporting as GRI, and 4) 
Process standards that define processes to enable the creation of management system around sustainability as ISO26001.

For the aforementioned reason, diffusion analysis with respect to environmental and other standards, such as quality management standards, has been performed and the potential consequences of future standards in managerial and academic issues have been noted (Franceschini et al., 2004; Marimon et al., 2006; Casadesus et al., 2008; Marimon et al., 2010; Casadesus et al., 2010; Francheschini et al., 2010; Llach et al. 2011). Nevertheless, the study of the diffusion of social standards is quite scarce. To date, to the best of our knowledge, studies have been conducted in a descriptive way (e.g., Knudsen, 2013; Rajabzadeh, 2013) and there is little research regarding how diffusion happened (see Marimon et al., 2012; Alonso-Almeida et al., 2012 for GRI reporting). As Gilbert et al. (2011) asserted, more information is needed regarding the diffusion of these standards to better understand the phenomenon and its impacts.

As far as we know, no other social standard's diffusion has yet been studied. Consequently, there still seems to be room for improvement in this matter, with the aim of identifying diffusion patterns to forecast future trends and the market's disclosure requirements.

This paper is focused on the diffusion of SA8000. This standard has been selected for three reasons. First, this standard is one of the world's first auditable social certification standards for decent workplaces and human rights across all industrial sectors (Gilbert et al., 2011; SAI, 2013). Second, it is one of the most widely used standards in social issues worldwide (Leipziger, 2003; Rajabzadeh, 2013). Finally, according to Lin (2012), SA8000 is the most influential standard in the fields of human rights and labor. Moreover, this standard can help governments adopt legal measures in a proactive way because this 
standard could address changes in their social environments from a social viewpoint. Social standards such as SA8000 are considered soft law. Nevertheless, Gilbert et al. (2011) explained these can become harder over time by means of being selected as a prerequisite for doing business in some industries, or acting in areas where enforceable legal regulation has not yet been enacted.

The diffusion analysis of the standard and its adoption model will enable understanding of the motivations for its implementation and the expected benefits. Regardless, this is not the aim of this paper. It would be excessively pretentious to have this as an additional objective. Nevertheless, this understanding is an important issue that should be addressed in future research.

To analyze the diffusion pattern of the SA8000 standard, the logistic curve is adapted using the available evolution certificate data provided by Social Accountability International (SAI, 2012). Thus, this work pursues three main objectives. First, an analysis will be developed to explain and predict the diffusion of the SA8000 on a worldwide scale. The second will be to compare and analyze SA8000 diffusion among the main industry activities. Finally, an exploratory analysis will be conducted to describe the diffusion stage itself and compare it with other management standards, with the aim of evaluating the differences or similarities in diffusion. We assume that understanding the diffusion of other standards will help enrich the analysis of the SA8000 standard diffusion.

This study contributes to the previous research in three ways. First, this study increases the understanding of SA8000's diffusion. Second, this study provides an exploratory descriptive analysis of the current SA8000 diffusion worldwide in both macro- and microanalyses compared with other standards' worldwide diffusion worldwide. Finally, 
this study identifies future trends in SA8000 diffusion. Therefore, studying the diffusion of SA8000 could be useful for the standard itself, for companies, and for society. First, the study of the standard could identify areas of improvement in diffusion to prioritize actions. Second, companies could find ways to strengthen their business. Finally, societies with more companies engaged in social issues could improve the quality of life of their citizens.

Pursuant to aforementioned objectives, the remainder of the paper is organized as follows. The second section provides a review of the literature regarding SA8000. The methodology employed and the statistical results are explained in the third section. The discussion of the results and conclusions are presented in the fourth and fifth sections, respectively.

\section{Literature review}

\subsection{Social Accountability 8000 standard foundation}

Social Accountability International (SAI) is an international non-profit multi-stakeholder organization founded in 1997. Its mission is to advance the human rights of workers and to eliminate sweatshops by promoting ethical working conditions, labor rights, corporate social responsibility, and social dialogue around the world. To that aim, SAI is developing and implementing a socially responsible standard, SA8000 (SAI, 2013). The organization has an advisory board with representatives from multinational firms, international unions, and NGOs (O'Rourke, 2006). SA8000 is formulated in accordance with the treaty of the International Labor Organization (ILO), the Universal Declaration of Human Rights, and the UN Convention of Child Rights (SAI, 2013). This standard is supported under nine

pillars (see Figure 1), which define guidelines for auditing ethical workplace conditions 
throughout a global supply chain (Gilbert and Rasche, 2007). Therefore, SA8000 is focused on the scope of work with the aim of improving working conditions of the global labor force (Tsai et al., 2011). In fact, Tsai et al. (2011, pp. 2) has defined the SA8000 standard as "the first to authenticate international CSR with the objective of imposing humanism on market economics". All its requirements are generic and applicable to all type of organizations (Rajabzabeh, 2013).

Furthermore, the SA8000 standard includes an accreditation process. As SAI (2013) asserted "accreditation is a process similar to licensing, wherein SAAS evaluates an applicant certification firm's capacity to thoroughly audit a workplace for compliance with SA8000. This process includes an audit of a company's written policies, procedures and documentation. Accreditation applicants must demonstrate adherence to SAAS accreditation criteria."

$* * * * * * * * * *$

Insert Figure 1 over here

SA8000 provides a number of procedures that help companies engage with their stakeholders (Rohitratana, 2002). For that reason, Gilbert and Rasche (2007) noted that stakeholders are the main addressees of standardized ethics initiatives such as SA8000. Every five years SAI revises the SA8000 standard to ensure its continued relevance and adoptability. This process is conducted in accordance with the ISEAL Code of Good Practice for Setting Social and Environmental Standards (the Code). The new standard is under review and will be known as SA8000:2014. 
From the stakeholder viewpoint, there are three important features of SA8000. First, it provides guidance regarding taking stakeholders' interests into account in a practical manner. This SA8000 Guidance document is intended to provide some interpretation and examples of application of the SA8000 Standard's requirements for auditors and other users of the Standard. It is not intended to be comprehensive and does not include all matters of interpretation or implementation that arise when applying the SA8000 Standard to the workplace. Second, it encourages stakeholders to work with the company to achieve long-term benefits. Finally, it helps companies understand why stakeholders need to be accounted for (Gilbert and Rasche, 2007). These authors also provided suggestions on how companies can engage stakeholders through the activities and new practices adopted in order to obtain a positive audit with regards to the SA8000 standard. Thus, Behnam and MacLean (2011) explained that companies seeking a positive audit have two options to implement SA8000, certification or a corporate program. In the first case, companies must have their individual facilities certified in compliance with the standard. In the second case, companies must ensure that goods are produced under decent working conditions.

Moreover, SA8000 provides a way to increase a company's international competitiveness given that products manufactured under this standard adhere to stricter social responsibility, humanism, and morality standards (Lin, 2012). Gilbert and Rasche (2007) noted three reasons for this statement. First, these initiatives provide information for the different stakeholders. Second, stakeholders should be participants in the implementation process. Finally, stakeholders act as watchtowers (Gilbert and Rasche (2007) called them watchdogs) for the implementation of the standard. 
Nevertheless, SA8000 is not free from criticism. On the one hand, one of the main problems is that the standard could be seen as representing only Western norms (Ciliberti et al., 2011) because it was created without taking into account stakeholders from developing countries (Fung, 2003; Gilbert and Rasche, 2007). Rasche (2012) also noted that this standard shows a lack of transparency because its reports are not public.

On the other hand, other authors (see Nieto and Fernandez, 2004) suggest that the adoption of SA8000 could simply be a temporary fad. Other problems are consistent with all management standards, such as requirements that are too vague and costly, especially to small companies (Gilbert and Rasche, 2007). Ciliberti et al. (2011) calculated an investment between $\$ 20,000$ and $\$ 40,000$ per company depending on the company's characteristics. In other words, Battaglia et al. (2010) stressed the barriers for small companies being mainly the cost, lack of CSR culture among top managers, and scant knowledge and expertise of CSR tools.

\subsection{Impacts of SA8000 in companies}

Heras-Saizarbitoria \& Boiral (2013) published an extensive review on the diffusion of some management standards, specifically focused on the two main meta-standards that have been more extensively adopted by organizations worldwide: ISO 14001 and ISO 9001. Their research provides clues to gauge the implementation motivations and benefits.

Some papers are focused on the technical impacts of ISO 14001, such as the analysis of Potoski and Prakash (2013), which assess the relationship between the number of ISO 14001 certifications in a particular country and the reductions in air emissions (sulfur dioxide, SO2) and water pollution (biochemical oxygen demand, BOD). 
Nevertheless, a lack of literature is detected regarded SA8000 benefits. A few recent papers have been found. One of these is written by Lin (2012). He found that this standard can help companies maintain business practices that comply with human rights laws. Thus, multinational companies could terminate relationships with subcontractors who provide bad working conditions. SA8000 drives ethical production given that adopters are required to provide basic protection to their workers. Then, according to Tsai et al. (2011), they could be known as "ethical manufacturers".

Moreover, globalization has led to the relocation of production from developed to developing countries where costs are lower and legislation is weaker. In a recent paper, Donaghey et al. (2014) claim that states that are offshoring destinations due to their lowcost labor advantages have an incentive to avoid constraining labor rules. In turn, multinational companies have ability in order to locate their production where constraining rules are lower (Rohdes, 1997). Public opinion is critical for companies that engage in unethical human rights behaviors outside of developed countries, yet do not exhibit the same practices in developed countries (Fuentes-García et al., 2008). Multinational companies are concerned about this issue because a number of companies are taken to court in the developing countries where the misconduct takes place. Therefore, companies can avoid government fines due to misconduct and improve their reputations. These benefits could be the key motivational factors for adopting the standard (Gilbert and Rasche, 2007). Thus, multinational companies can demand SA8000 implementation from their suppliers or subcontractors, but they do not need to implement the standard themselves when they do not engage in production (Rasche, 2009). In developed countries, human rights and working conditions are already more stringently regulated (Fuentes-Garcia et al., 2008; Ciliberti et al., 2008). 
Another benefit derived from this standard is the achievement of trust vis-à-vis stakeholders. This is one of the key challenges for multinational corporations (Gilbert and Rasche, 2007). Given that SA8000 clearly defines key definitions and requirements within the standard, companies' individual interpretations are reduced. Therefore, the standard could reinforce stakeholder trust (Gilbert and Rasche, 2007; Rasche, 2009). Thus, SA8000 seems to be aware of stakeholders' concerns in an extended sense. As an example, this standard is the only one that emphasizes the stakeholders related to suppliers and associations (Tsai et al, 2011).

Regarding suppliers, SA8000 provides a trust relationship that leads to lower human rights violations-related risk. Thus, relevant information can be exchanged among principal and agents in the supply chain, reducing moral hazard problems (Ciliberti et al., 2011). In addition, compliance with the standard can spread social behavior along the whole supply chain (Ciliberti et al., 2009).

Thus, companies should assure that all steps in the supply chain comply with SA8000 requirements and demand certification (Ciliberti et al., 2009). In fact, every SA8000 certified company should select and evaluate its suppliers on the basis of the fulfilment of this standard (SAI, 2013). International companies could impose SA8000 certification on their supply chain (both upstream and downstream) given that this social standard increases the traceability of key processes, facilitates the coordination of the supply chain, and reduces asymmetry and transaction costs. Although asymmetric information does not disappear, SA8000 certification increases trust and acts as a key driver in the relationship (Ciliberti et al., 2009).

To make the implementation more effective, Gilber and Rasche (2007) suggested cooperation with non-governmental organizations. The main reason is that NGOs can 
help companies understand local needs and make these standards manageable at a micro level.

Fuentes-García et al. (2008) enumerated the advantages related to this standard for workers and consumers. The workers obtain benefits in both developed and developing countries. On the one hand, workers in developing countries can see improved wages and working conditions (Stigzelins and Mark-Herbert, 2009, Bronner et al., 2012). Hanock (1998) and Thaler-Carter (1999) found, through business case studies, that SA8000 results in better trained workers, increased retention, and improved productivity. On the other hand, workers in developed countries could avoid business relocation. Additionally, customers would have improved visibility into what they are buying and ways in which product quality could improve. Additionally, compliance with the standard ensures that product has been produced in accordance with international legal acts (Rajabzabeh, 2013).

Finally, SA8000 could help modify the local context of a particular production facility (Ortmann and Salzman, 2002) and improve the local standard of living. Workers earning higher wages can increase their purchasing power (Fuentes-García et al., 2008) and drive economic advancements in a particular area, although research is not conclusive (Hiscox et al., 2008).

With a macro-viewpoint, some of the standard's aspects such as the promotion of freedom of association and collective bargaining can drive democratic reforms. In addition, the standard can reduce child labor (Cigno et al., 2002; Neumayer and de Soysa, 2005; Polaski, 2006) and improve the empowerment of women (Barrientos et al., 2003), thus helping to reduce the gender gap in these countries. 
In summary, the aim of this standard is to impact certain aspects of companies, stakeholders, and communities where companies are located. Therefore, given that developed countries usually have strict regulations and governmental control over companies in all issues related to the SA8000 standard, especially human rights, compliance to this standard will be more useful in countries where human rights are not well-respected, where it can act as a self-regulator for companies (Rache, 2012). Rasche (2010) also argues that standards such as SA8000 play a useful role promoting corporate responsibility, especially in those countries or areas where governments regulations are not strict or are expressed in general terms and not settled in detail. Human rights are "commonly understood as inalienable fundamental rights to which a person is inherently entitled simply because she or he is a human being" (Sepúlveda et al., 2004). According to the Human Rights Watch Report (2013), developing countries (Asian and Arab countries) and non-developing countries are the worst violators of basic human rights, although no place worldwide is free from blame. Therefore, our first proposition is:

Proposition 1: SA8000 certification will be more extensive and quickly diffused in countries where human rights are weak (developing countries).

Moreover, outsourcing has moved hard production from developed to developing countries. Hard production is defined as the production in manufacturing industries where more workers are required (Busse, 2002; Polaski, 2006). Indeed globalization is weakening the states' power of regulation and, at same time, engaging companies as agents in charge of negotiations with respect to their employees (Mueckenberger and Jastram, 2010). Thus, companies adopting such standards could exert pressure as political-economic actors whose behavior private regulations seek to affect (Knudsen, 2013). 
The degree of labor intensity is typically measured in proportion to the amount of human capital required to produce the goods/services; the higher the proportion of labor costs required, the more labor intensive the business is. Some authors (see, e.g., Busse, 2002; Polaski, 2006; Rasche, 2009; Rajabzabeh, 2013) noted that the activity sectors with higher labor intensity are mainly garment, textile, apparel, food, construction, or toys, among others. These industries are a supposed first step in the process of industrialization because they require low levels of investment and limited skills from workers (Polaski, 2006). Thus, the following proposition is stated:

Proposition 2: SA8000 will be more (extensive) and (quickly) diffused in laborintensive industries.

\subsection{Standards diffusion and trends worldwide}

The literature relating to the dissemination of different management tools and systems is extensive. The logistic curve model has been successfully used by academics to explain the diffusion of several management standards (Franceschini et al., 2004; Marimon et al., 2004, 2006, 2009, 2010 and 2012; Casadesus et al., 2008; Casadesus et al., 2010; Llach et al., 2011; Sampaio et al., 2011) with consistent and conclusive results.

Marimon et al. (2012) asserted that the logistic curve method was applied for the first time during the nineteenth century by the Belgian mathematician Verhulst in the field of biology to account for the growth of a population. Thus, "this model explains that the growth rate is at a maximum at the beginning, when there are few individuals in a population and little competition for resources, and the growth rate is reduced to zero 
once a certain population size is reached. This is the size of saturation that the available resources permit". The model follows the expression:

$$
N=\frac{N_{0} K}{\left(K-N_{0}\right) e^{-r_{0} t}+N_{0}}
$$

where $\mathrm{N}$ represents the number of individuals in a population, which is a function of time. $\mathrm{N}_{0}$ represents the number of individuals at the starting point. $\mathrm{K}$ is the maximum level that can be reached, i.e., the saturation level. The initial growth rate is determined by $\mathrm{r}_{0}$, and the independent variable, time, is represented by $t$.

Previous research has shown that the model explained the diffusion of the ISO 9001 standard, related to quality management (Franceschini et al., 2004; Marimon et al., 2006), and the diffusion of ISO 14001 (Marimon et al., 2006), which addresses environment management. The model also fits when the data are analyzed by country or by activity sector (Llach et al., 2011, Marimon et al., 2011). Both standards have been popular and successful since their publication. It is widely accepted that the ISO 9001 series of standards is the most popular reference model for setting up quality assurance systems in organizations. This standard was first established in 1987, but its worldwide success was a result of a revision carried out in 1994. ISO 14001 was published later, but still in the past century. Nevertheless, the first certification of SA8000 was in 2000 , and there is currently enough data to analyze and compare its evolution against those previous management standards.

The diffusion of recent standards related to social responsibility, such as GRI, has also been studied with satisfactory results (Marimon et al., 2012). Thus, the following proposition is posed: 
Proposition 3: SA8000 is disseminated following the same diffusion pattern as other management standards.

The diffusion of social management standards such as GRI has been found to also follow the logistic curve pattern (Marimon et al., 2012). As the SA8000 standard is quite a bit younger than the ISO family of standards, we also pose an additional proposition:

Proposition 4: SA8000 is in its expansionist state in pioneer industries and countries.

\section{Methodological note}

The data used in this paper was provided by Social Accountability International (SAI, 2012). In June 2012, 3,083 certified facilities were reported by SAI. It is important to note that 96 of them, from Pakistan, were suspended. We removed all of these certifications and were left with 2,987. Sixty-five countries and 66 activity sectors were represented. The aforementioned logistic curve was regressed on the worldwide data, showing satisfactory alignment and confirming that this pattern is useful in explaining the diffusion of SA8000 (Figure 2). The saturation is estimated in 6,270 certifications, and approximately $95 \%$ of its saturation (5,956 certifications) will be reached in 2020 .

\section{$* * * * * * * * * *$ \\ Insert Figure 2 over here}

\section{Results}

This chapter is structured into three subsections. The first subsection presents the diffusion of the SA8000 by the top three activity sectors (apparel, construction and textiles). The objective is to analyze the degree of saturation of these activity sectors and 
to classify them according to the classification proposed by Rogers (1995). The second subsection, following the same method as the previous subsection, presents the results by the top three countries (Italy, India and China). Finally, the last subsection presents the instability and the concentration indices of the market to understand how it has evolved during the period studied.

\subsection{Diffusion of the SA8000 by sector of activity}

The next step in the analysis was focusing on the top three activity sectors in the ranking (Figure 3) and the top three countries in corresponding rankings (Figure 4). The sectors at the top of the ranking by activity use labor intensively: apparel, construction, and textiles, as Rasche (2009) and Rajabzabeh (2013) discovered. All of them show satisfactory alignment when fitting the logistic curve. Their saturations are quite similar, ranging between 553 and 645. Additionally, in all cases, their saturation levels in 2011 are far from $95 \%$, ranging from $38.1 \%$ to $65.8 \%$. Their $95 \%$ saturations will be attained between 2016 and 2019. Rogers (1995), classifies the innovation adopters in different categories, from "innovators" to "laggards" and represents this adoption over time in an S-curve graphic.

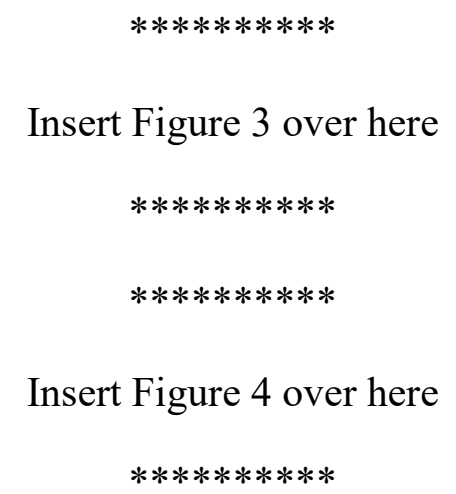

\subsection{Diffusion of the SA8000 by country}


In the case of countries, the top positions correspond to Italy, India, and China, where, with the exception of Italy, all of them have a "well-acknowledged problem" in terms of working conditions and human rights (Rasche, 2009; Human Rights Watch, 2013). Their saturations range from 970 to 1,116, and the percentages of these saturations in 2011 range from $43.1 \%$ to $80.6 \%$. Figure 5 includes two more countries: Romania and Brazil. Except for Italy, all are developing countries. Hence, Proposition 1 is partially supported: SA8000 is more diffused in countries where human rights are weak. The case of Italy is surprising and deserves an explanation. The SA8000 standard has been supported by the government in Italy and particularly by regional governments. Tuscany has been promoting and supporting specific fiscal measures for the adoption of SA8000 certification (Iseal Alliance, 2008) and other national incentives (Ciliberti et al., 2008). These last authors also noted cultural factors. On the other hand, Rasche (2009) suggests that the government drove this standard in an effort to solve problems related to child labor and salaries.

Similar conclusions are drawn by analyzing the sectors. Regarding their positions in the ranking, it seems obvious that all these sectors, which are "pioneers" in the use of the SA8000 standard, are highly labor-intensive. It is interesting to note that, with respect to the regression statistics, construction and textiles are in their first steps along their respective logistic curves (expansionist state). Substantial growth in the number of SA8000 certified facilities in these sectors is expected. The model is well-suited to this diffusion phenomenon. Figure 6 includes two additional sectors, which are also laborintensive, to show the top five sectors and provide some clues supporting proposition 2: the SA8000 standard is more diffused in labor-intensive sectors. 
At this point, we can state that the SA8000 standard's diffusion follows the logistic curve, supporting Proposition 3. Proposition 4 is also supported with previous analyses: the logistic curve has been successfully applied to pioneer sectors and countries.

Figures 5 and 6 show two analogous analyses performed at the same time: the first one depicts countries, and the second depicts the activities sectors. Figure 5 is the corresponding table analyzing the diffusion phenomenon by country. These five countries account for $82.3 \%$ of the SA8000 reports in 2011, indicating a greater concentration.

Insert Figure 5 over here

The SA8000 standard has been adopted by 66 different sectors, ranging from "accessories" to "writing instruments". Figure 6 displays a positive trend in the monitoring of SA8000 in each of the top five sectors (together, these sectors account for 44.1 per cent of the SA8000 reports in 2011), with "apparel" being the leading sector in recent years.

$* * * * * * * * * *$

Insert Figure 6 over here

The dashed line in Figure 5 is much closer to the "total" line than in Figure 6.

At this point, we assume that there is enough evidence to support Proposition 3. SA8000 diffusion follows the same pattern as the diffusion of other standards, such as GRI. 
However, we are cautious in this claim because this is an exploratory paper and more analysis should be performed in the near future.

Following the methodology proposed by Marimon et al. (2011) to compare the diffusion of a standard among different activity sectors and countries, the evolution of instability and the concentration of the rankings of the SA8000 certifications have been studied. A complementary analysis was performed using commonly used indicators to determine the degree of competition that companies experience in a given market (e.g., indicators of the degree of instability and of concentration in the relevant sectors).

\subsection{Instability and concentration indices of the market}

\section{Instability index}

The level of stability indicates the relative position of each company over time in the market, whereas the degree of concentration refers to the market share enjoyed by the leading companies. Both concepts are applied to companies from each sector of economic activity in relation to the total number of certifications. Thus, the same tools used to describe certifications among companies are applied to certifications among sectors. Figure 7 illustrates the evolution of the SA8000 certification rankings by sector of activity, showing the seven sectors that were in the top positions in 2011.

$* * * * * * * * * *$

Insert Figure 7 over here

$* * * * * * * * * *$

Analogous analysis is performed in Figure 8, regarding the evolution in the ranking positions over time by countries. 
Insert Figure 8 over here

As indicated in Figure 7, the five highest-ranked sectors have maintained their positions in recent years. Figure 7 confirms what is explicitly shown in Figure 5: the relative positions in the rankings are becoming more stable. The instability index, defined below, has been used throughout this chronological series:

$I=\frac{1}{2} \sum_{i=1}^{n}\left|s_{i 2}-s_{i 1}\right|$

where $s_{i 1}$ and $s_{i 2}$ are the quotas of sector i during periods 1 and 2, respectively. The index ranges from zero (minimum instability) to one (maximum instability). The value $I=0$ relates to a situation in which all the sectors maintain their share; the value $I=1$ corresponds to a situation in which all the sectors competing in the initial period are out of the market in the second period. The trend is evolving toward lower values of instability (Figure 9). The SA8000 standard is maturing, and over time, the positions in the rankings are becoming more stable, confirming that the positions of the most important sectors stabilize over time. The same analysis was conducted by country, confirming also that the positions of the countries are becoming more stable (see dashed line in Figure 9).

$* * * * * * * * * *$

Insert Figure 9 over here

$* * * * * * * * * *$

The same evolution is observed in the trends of instability indices in the cases of ISO 9000, ISO 14000, and GRI certifications (Marimon et al., 2006, 2011 and 2012). 
Additionally, the values of instability indices in 2011 and 2010 for these standards fall within a narrow range: between 0.055 (the case of SA8000 analyzed by country) and 0.0925 (the case of the ISO 9000 standard).

\section{Concentration index}

For the purpose of studying the degree of concentration, the Herfindahl index was used. Greer (1992) and Cabral (1997) are among those who maintain that this index constitutes a useful means of analyzing concentration even though it was originally designed to measure the concentration of market share held by particular suppliers in a market. The index is defined as follows:

$$
H=\sum_{i=1}^{n} s_{i}^{2}
$$

where $s_{i}$ is the quota of sector $\mathrm{i}$, and $\mathrm{n}$ is the number of sectors. The value of $H$ varies between $1 / \mathrm{n}$ (minimum concentration) and 1 (maximum concentration). In our case, the minimum level is 0.015 in both cases: $(1 / 66)$ referred to industries and $(1 / 65)$ to countries. Figure 10 shows the evolution of this concentration index, which is similar to that observed in the case of the instability index. Over time, the values begin to indicate a low level of concentration. Although the figures for the different sectors have tended to level out, there is still a significant range between the apparel sector, with a 14.61 per cent share for 2011, and pharmaceutical services, with a 0.04 per cent share. On the other hand, as it has been noted, the concentration index analyzed by country is higher.

Compared with concentration indices analyzing the evolution of other management standards such as ISO 9000, ISO 14000, or GRI, we observed similar values of the indices in 2011 and 2010 (Marimon et al., 2006, 2011 and 2012). The Herfindahl index cannot 
be compared directly because its minimum depends on the number of items in the list analyzed. However, an "escalated Herfindhal" can be calculated by changing the scales and forcing a range between zero and one. This indexed range is also narrow: between 0.03 for the evolution of the ISO 14000 standard, and 0.18 for SA8000 by country evolution.

\footnotetext{
$* * * * * * * * * *$
}

Insert Figure 10 over here

\section{Discussion of the results}

Developing countries are leading the ranking of SA8000. India, China, Romania and Brazil are keeping consistently the top positions. Particularly anecdotal and interesting is the case of Italy, which is in first position of the ranking. This requires a specific explanation that is provided in this section. Italy alone has a share of 31.3 in percentage of the SA8000 at worldwide scale, whereas the following four countries together represent the 48.3 in percentage. We will discuss the phenomenon at worldwide scale in first term and at activity sector level in second term. Although both analyses should be interpreted together, due to the fact that the developing countries are attractive for those activity sectors intensive in labor, (e.g., apparel, construction, textiles) because the lowcost labor, resulting in a double explanation for the spreading of SA800 in developing countries and particularly in high intensity labor sectors. The first analysis addressed to shed light in order to gauge the first proposition, whereas the second in directed in order to answer to the second proposition. 
Governments have developed a mass of legislation on social and environmental issues on an international scale during the last several decades, especially in developed countries (Ciliberti et al., 2009; Rasche, 2010). Governments respond to a general sensitivity to these issues in these societies. However, this sensitivity does not have the same support in developing countries.

Donaghey et al. (2014) explains how globalization changes the traditional tripartite tension model among labor, state and employees, resulting in a lack of labor regulation. Those states that attract investments due to its low-cost labor have an incentive to avoid constraining labor rules. In order to fill this government gap on this regulation, Rasche (2010) sees SA8000 and other voluntary standards as a solution.

On the other hand, some consumers in developed countries have deep concerns regarding the social orientation taken in developing countries where the goods they buy are made. These consumers find an extra value in those services or goods that are provided with great respect to human rights. This pressure has become an influence for multinational corporations and is taking an important role in the dynamics of labor governance. Where the weak legislation of developing countries is losing power, the customers of the developed countries are gaining momentum (Donaghey et al., 2014). Therefore, it seems that governments in developing countries seem reluctant to recommend and legislate environmental care or labor force conditions or to confront corruption.

Moreover, standards are rules of a particular type: they spread because of the 'general, abstract and timeless ideas' they are based on (Brunsson et al., 2000). The standards that become successful show that have been accepted by their own power, not imposed by legislation. Demortain (2008) adds another clue in order to understand it, claiming that scientists are key actors of standardisation, because of their ability to include potential 
users and standard-setters in the process of replicating practices. Thus, initiatives such as SA8000 are approaches to complement legislation in countries where legislation is weak in those particular issues (Gilbert and Rasche, 2007). Moreover, these types of standards are benchmarks in CSR set by other organizations (Tsai et al., 2011). Thus, they shape firm behaviors by means of coordinating the interactions of firms from several countries and types of stakeholders and guiding firms' activities (Terlaak, 2007). Hence, it can be concluded that these standards have made their way into managers' agendas (Rasche, 2009). This paper examined the diffusion of SA8000 and uncovered some remarkable findings.

The potential geographic scope of the SA8000 standard is global, however, it could be used more widely in countries where work conditions are below the minimum level required. The main reason is that sometimes governments do not want or cannot adopt legally enforceable hard solutions, and in these cases standards run as institutional action to promote corporate responsibility (Rasche, 2010) and, therefore, act a supplement of norms (Rasche, 2012). Usually, voluntary social initiatives as ISO14001 or SA8000 are created by private-decentralized institutions whose can not make responsible for their enforcement (Terlaak, 2007).

Thus, SA8000 has been more strenuously adopted in developing countries, such as China and India. As Lin (2012) asserted, China has adopted SA8000 to improve labor conditions and change the negative image of its companies regarding low labor standards and insufficient protection.

Nevertheless, surprisingly, SA8000 has also been widely diffused in some developed countries, such as Italy. Ciliberti et al. (2008) noted some possible explanations regarding why SA8000 is so widely used in Italy. First, it is very easy to achieve this standard 
because regulations on working conditions in developed countries exceed SA8000 requirements. Second, Italian business culture is very social and the government supports social initiatives in companies with financial and welfare incentives. Finally, some Italian regions provide additional financial incentives to implement social standards. Rasche (2009 quoted Leipziger, 2001) explained that SA8000 was heavily adopted in Italy because "child labor and wages are known problems there". This could explain the government support in Italy and why, from the beginning, it was acknowledged that, although it can never be a complete solution, SA8000 could provide the willingness to look for solutions and actions (Rasche, 2010).

After these commentaries at country level, we focus now in the sector activity spread of the standard.

As proposed, SA8000 is more widely used in labor-intensive industries. Hence, the adoption of this standard favors workers' conditions, especially in labor-intensive industries. Thus, as Rasche (2010) asserted, the role of this standard is not superfluous because it acts as a soft law and can reinforce better working conditions in global supply chains. Polaski (2006) explained that the apparel industry has quickly grown during the past two decades in Asian countries.

The third issue to deal with is related to diffusion model in itself. This provides evidences related to the third and fourth propositions. Previous analyses regressing different data (e.g., evolution of SA8000 certificates per country and per activity sector) to the logistic curve allows to confirm that this pattern is useful to explain the diffusion phenomenon. The data fits with the s-shaped logistic curve in most of the situations analyzed. Moreover, the data available confirms that the phenomenon is now in the expansionist phase of the curve. 
Regarding the diffusion, SA8000 was disseminated following the same diffusion as other management standards, such as ISO 14001 and GRI (Marimon et al., 2010; 2012). This finding corroborates that this method is useful in identifying patterns of diffusion, and especially useful in explaining the possible future of the standard. Furthermore, similar values for instability and concentration indices are found in comparison with other standards, such as ISO 9000, ISO 14000, and GRI certifications.

Moreover, our findings indicate that SA8000 is currently growing in pioneer industries and countries. This finding suggests that, in the near future, more companies will adopt this standard, as is the case with other standards (see Marimon et al., 2006; Casadesus et al., 2008; Marimon et al., 2010; Casadesus et al., 2010), given that it seems far from the saturation point even in pioneer countries and industries with the same pattern. In other words, while working conditions and human rights in developing countries continue to be "weak", the SA8000 certification will keep growing in these countries and industries. Therefore, we could conclude that SA8000 follows a similar pattern as other standards and, as consequence, a growing trend is expected in next years since is still in its infancy or first steps. According to Rogers (1995), diffusion is the process that explains how innovation is spread through certain channels over time within certain populations of potential adopters. Since then, it has been common to use the terminology that Rogers suggested for the different adopters of innovation, depending on when they adopt the innovation. The four groups proposed by Rogers are: "Innovators", "Early adopters", "Late majority", and "Laggards", depending on when they adopt the innovation. Thus, the actual organizations that have adopted SA8000 standards are innovators and early adopters. 
In the near future, when the diffusion of the standard achieves the lasts steps proposed by Rogers, the real impact of this standard with respect to production, workers, and communities will most likely need to be analyzed. In addition, this analysis could provide arguments to reinforce or change some current requirements.

Both instability and Herfindahl indices have shown values similar to other standards in a more mature state (Marimon et al., 2010, 2012; Llach et al., 2011). This finding suggests that SA8000 has been adopted more quickly than other standards and in a more homogeneous way. A possible explanation is that SA8000 is designed to integrate the standard into existing management systems and practices in companies. It is important to take into account that both China and India are in pioneer positions in a number of ISO 9001 and ISO 14001 certifications. Additionally, these management standards have been widely diffused worldwide in the food, textile, and construction industries (Bodas, 2009; Llach et al., 2011; Alonso-Almeida et al., 2012). Therefore, the learning process followed for other management standards could help the SA8000 standard be implemented faster. In summary, SA8000 adoption can be expected to increase in the next years in the same pattern of behavior as other standards, including in the countries and industries where higher adoption has already occurred, but other developing countries and industries can also emerge. These findings also reinforce the idea that certain drivers, such as globalization, legal conditions, or external pressures could increase or decrease the rate of adoption of this standard, which is used to develop closer and more trusting relations with stakeholders.

\section{Conclusions}


The findings of this study provide one major contribution and trends that deserve more detailed explanation. The main conclusion is that SA8000 follows a similar pattern as other standards; thus a growing trend in the near future, at least in developing countries, is expected. This situation could offer "a mechanism for companies to address complaints raised by activist groups, and concerns among consumers, about labor practices and working conditions in such countries" (Hiscox et al., 2011, pp.5).

Regarding to the future development of the standard, the SA8000 diffusion is in its expansionist state in pioneer industries and countries. The activity sectors that are leaders in the ranking of SA 8000 certificates are in the first steps in the "S-curve" and accordingly are labelled as "Innovators" and "Early adopters", following Rogers' notation. Analogously, the same phenomenon can be observed when analyzing by countries. This implies that a considerable increase is expected in terms of SA8000 new adopters in the near future. In addition, this growth trend supposes that other countries and industries are emerging and, at present, are in their infancy and sooner or later will spread. There is no doubt the diffusion will induce a specialized business development, such as a consultancy that implements the policies instilled by the SA8000 standard.

Moreover, it is worthwhile to outline the challenges that the adoption of the SA8000 standard may face in the near future. Based on the findings of this research, these challenges would primarily concern three important issues. First, the SA8000 standard must be more flexible to accommodate the differing perspectives of cultures and traditions (Rasche, 2009). Thus, the current SA8000 standard could be considered a starting point, but real efficacy requires more control in third-party monitoring of workplace conditions throughout a company's supply chain, given that the monitoring is a weakness of the system (Ciliberti et al., 2009). Second, another challenge is to increase 
the dialogue with stakeholders (Gilbert and Rasche, 2007; Rasche, 2010). Finally, previous research found that the SA8000 framework is predominantly taken up by large firms. Therefore, strong efforts should be made to include more small companies from developing countries.

It seems that social management standards are practical options to use to develop corporate social responsibility (Rasche, 2010). The standards become useful and, consequently, become popular and spread extensively because the stakeholders find them useful. In the case of SA800, the standard may provide enough evidence to consumers regarding the sensitivity of manufacturers of goods or providers of services to social issues. Conversely, from the producer point of view, the standard may be the instrument to use to inform its market regarding its strategy and real behavior on these issues. However, given the exploratory nature of this study, it is strongly recommended that future research establish stronger evidence for the role of this standard.

It will be of interest to find motivations and enablers to the adoption of the SA8000 standard in the top three sectors of activity and countries, as well as to examine the impact on benefits provided. For this purpose, empirical studies should be developed in order to shed light on these types of issues.

For that reason, future research should include more empirical research in both qualitative and quantitative analysis to measure and understand the effects of SA8000 in specific cases.

\section{References}


Alonso-Almeida, M.M., Llach, J. \& Marimon, F. (2012). A Closer Look at the 'Global Reporting Initiative' Sustainability Reporting as a Tool to Implement Environmental and Social Policies: A Worldwide Sector Analysis. Corporate Social Responsibility and Environmental Management, DOI: 10.1002/csr.1318.

Barrientos S. \& Dolan, C. (2003). A Gendered Value Chain Approach to Codes of Conduct in African Horticulture. World Development, 31 (9), 1511-1526.

Battaglia, M., Bianchi, L., Frey M. and Iraldo, F. (2010). An Innovative Model to Promote CSR among SMEs Operating in Industrial Clusters: Evidence from an EU Project. Corporate Social Responsibility and Environmental Management 17, 133-141.

Behnam, M., \& MacLean, T. (2011). Where is the accountability in international accountability standards?: A Decoupling Perspective.Business Ethics Quarterly, 21(1), $45-72$.

Bodas, I. (2009). The Diffusion of ISO 9000 and 14001 Certification, Cross Sectoral Evidence from Eight OECD Countries, Paper Presented at the Summer Conference 2009. Copenhagen Business School, Denmark. June 17-19.

Brunsson, N. and B. Jacobsson (2000). 'The contemporary expansion of standardization'. In A World of Standards. N. Brunsson and B. Jacobsson (eds), 1-17. Oxford: Oxford. University Press.

Brunsson, N., Rasche A., and Seidl, D. (2012). Studies The Dynamics of Standardization: Three Perspectives on Standards in Organization. Organization Studies, $33(5-6) 613-632$.

Busse, M. (2002). Do Labor Standards Affect Comparative Advantage in Developing Countries?. World Development, 30 (11), 1921-1932.

Cabral L. 1997. Economía Industrial 1st ed. McGraw-Hill: Madrid. 
Casadesus, M., Marimon, F. \& Heras, I., (2008). Countries behavior regarding to the diffusion of ISO 14000 standards. Journal of Cleaner Production, 16, 1741-1754.

Casadesus, M., Marimon, F. \& Alonso, M., (2010). The future of standardised quality management in tourism: evidence from the Spanish Tourist sector. Service Industries Journal, 30(14), 2457-2474.

Cigno A. \& Rosati F. C. (2002). Does Globalization Increase Child Labor?. World Development, 30(9), 1579-1589,

Ciliberti, F., de Groot, G., de Haan, J. \& Pontrandolfo, P. (2009).Codes to coordinate supply chains: SMEs' experiences with SA8000, Supply Chain Management: An International Journal, 14(2), 117 - 127

Ciliberti, F., Pontrandolfo P. \& Scozzi B. (2008). Logistics social responsibility: Standard adoption and practices in Italian companies. International Journal Production Economics, 113, 88-106.

Delmas, M., \& Montes-Sancho, M. 2011. An institutional perspective on the diffusion of international management system standards: The case of the environmental management standard ISO 14001. Business Ethics Quarterly, 21: 103-32.

Demortain, D. (2008). Standardising through concepts: the power of scientific experts in international standard-setting. Science and Public Policy, 35(6), 391-402.

Donaghey, J., Reinecke, J., Niforou, C., \& Lawson, B. (2014). From employment relations to consumption relations: balancing labor governance in global supply chains. Human Resource Management, 53(2), 229-252.

Franceschini, F., Galetto, M. \& Gianni, G. (2004). A new forecasting model for the diffusion of ISO 9000 standard certifications in European countries. International Journal of Quality \& Reliability Management, 21(1), 32-50. 
Fuentes-Garcia, F.J., Nuñez-Tabales, J.M. \& Veroz-Herradon, R. (2008). Applicability of Corporate Social Responsibility to Human Resources Management: Perspective from Spain. Journal of Business Ethics, 82, 27-44.

Fung, A. (2003). Deliberative Democracy and International Labor Standards. Governance:An International Journal of Policy, Administration, and Institutions, 16(1), $51-71$.

Gilbert, D.U. Rasche, A. and Waddock S, (2011). Accountability in a Global Economy: The Emergence of International Accountability Standards. Business Ethics Quarterly 21:1, pp. 23-44

Gilbert, D.U. \& Rasche, A. (2007). Discourse ethics and social accountability - the ethics of SA 8000. Business Ethics Quarterly, 17(2), 187-216.

Greer DF. 1992. Industrial Organization and Public Policy, 3rd ed. MacMillan: New York.

Hanock, S. (1998). Fair's Fare. Supply Management, 3(22), 22-25.

Heras-Saizarbitoria, I. and Boiral, O. (2013). ISO 9001 and ISO 14001: Towards a Research Agenda on Management System Standards. International Journal of Management Reviews, 15(1), 47-65.

Hiscox, M. J. and Broukhim, M. and Litwin, C. and Woloski, A. (2011). Consumer Demand for Fair Labor Standards: Evidence from a Field Experiment on eBay Available at SSRN:http://ssrn.com/abstract=1811788 or http://dx.doi.org/10.2139/ ssrn.1811788.

Hiscox, M.J., Schwartz, C. and Toffel, M.W. (2008), "Evaluating the impact of SA 8000 certification”, working paper, Harvard University, Boston, MA.

Human Rights Watch (2013). World Report 2013. Events of 2012. Available on www.hrw.org. Accessed in April 2, 2013. 
Iseal Aliance,(2008). Tuscany Region (Italy) and the SA8000 Standard for Social Accountability. Governmental Use of Voluntary Standards. Case Study 10. http://www.sa-intl.org/_data/n_0001/resources/live/SAI_SA8000Tuscany.pdf

Knudsen, J. S. (2013). The Growth of Private Regulation of Labor Standards in Global Supply Chains: Mission Impossible for Western Small- and Medium-Sized Firms?. Journal of Bussiness Ethics 117:387-398.

Lin, W. (2012). Study on the Relationships between Corporate Social Responsibility and Corporate International Competitiveness. Energy Procedia, 17, 567-572.

Ligteringen, E. \& Zadek, S. (2004). The future of corporate responsibility standards. Accounting Forum, 4, 6-17.

Llach, J., Marimon, F. \& Bernardo, M. (2011). ISO 9001 diffusion analysis according to activity sectors. Industrial Management \& Data Systems, 111(2), 298-316.

Marimon, F., Casadesus, M. \& Heras, I. (2004). A Dynamic Model for the Diffusion of ISO 9000 and ISO 14000 Standards, Proceedings of the International Conference on Modelling \& Simulation, Valladolid, Spain.

Marimon, F., Casadesús, M. \& Heras, I. (2006). ISO 9000 and ISO 14000 standards: an international diffusion model. International Journal of Operations and Production Management, 26(2), 141-165.

Marimon, F., Casadesús, M. \& Heras, I. (2010). Certification Intensity Level of the leading nations in ISO 9000 and ISO 14000 standards. International Journal of Quality \& Reliability Management, 27(9), 1002-1020.

Marimon, F., Llach, J. \& Bernardo, M. (2011). Comparative analysis of diffusion of the ISO 14001 standard by sector of activity. Journal of Cleaner Production, 19(15), 1734-1744. 
Marimon, F., Alonso-Almeida, M., Rodriguez, M., \& Cortez. K. (2012). The worldwide diffusion of the global reporting initiative: what is the point?. Journal of Cleaner Production, 33, 132-144.

Mueckenberger, U., \& Jastram, S. (2010). Transnational norm-building networks and the legitimacy of corporate social responsibility standards.Journal of Business Ethics, 97(2), 223-239.

Neumayer E. \& Soysa I. (2005). Trade Openness, Foreign Direct Investment and Child Labor. World Development, 33(1), 43-63.

Nieto, M. \& Fernández, R. (2004). Responsabilidad Social Corporativa: la ultima innovacion en management. Universia Business Review 1, 28-39.

O’Rourke, D. (2006). Multi-stakeholder Regulation: Privatizing or Socializing Global Labor Standards?. World Development , 34(5), 899-918.

Ortmann, G. \& Salzman, H. (2002). Stumbling Giants - The Emptiness, Fullness, and Recursiveness of strategic Management. Soziale Systeme, 8(2), 205-230.

Polaski, S. (2006). Combining Global and Local Forces: The Case of Labor Rights in Cambodia. World Development, 34(5), 919-932.

Potoski, M. and Prakash, A. (2013). Do Voluntary Programs Reduce Pollution? Examining ISO 14001's Effectiveness across Countries. Policy Studies Journal, 41(2), 273-294.

Rajabzadeh, M. (2013). Statistical analysis of certification process of international standard SA 8000 on social accountability. The Journal of International Social Research, Volume: 6 Issue: $24,306-315$.

Rasche, A. (2012). Scaling up Sustainability-The Role of Voluntary Standards. CBS Sustainability Quarterly, (3), 26-28. 
Rasche A. (2010). The limits of corporate responsibility standards. Business Ethics: A European Review, 19(3), 280-291.

Rasche A. (2009). Toward a Model to Compare and Analyze Accountability Standards - The Case of the UN Global Compact. Corporate Social Responsibility and Environmental Management, 16, 192-205.

Rhodes, M. (1997). The welfare state: International challenges, external constraints. In M. Rhodes, P. Heywoow, \& V. Wright (Eds.), Developments in west European politics (pp.57-74) New York, NY: Macmillan Press.

Rohitratana, K. (2002). SA 8000 - a Tool to Improve Quality of Life. Managerial Auditing Journal, 17(1/2), 60-64.

Rogers, E.M. (1995). Diffusion of Innovations”. The Free Press, New York, NY.

SAI, Social Accountability International. (2008b). What does SAI do? http://www.saintl.org/index.cfm?fuseaction=PageviewPage\&pageId=487\&parentID=472\&nodeID $=1 \mathrm{i}$ ; accessed 18/03/2013.

Sampaio, P., Saraiva, P. \& Rodriguez, A. (2011). ISO 9001 certification forecasting models. International Journal of Quality \& Reliability Management, 28(1), 5-26.

Sepúlveda, M., van Banning, T., Gudmundsdóttir, G., Chamoun, C. \& van Genugten, W.J.M. (2004). Human rights reference handbook (3rd ed. rev. ed.). Ciudad Colon, Costa Rica: University of Peace.

Stigzelius, I., \& Mark-Herbert, C. (2009). Tailoring corporate responsibility to suppliers: Managing SA 8000 in Indian garment manufacturing. Scandinavian Journal of Management, 25, 46-56. 
Terlaak, A. (2007). Order without law? The role of certified management standards in shaping socially desired firm behaviors. Academy of Management Review, 32 (3), 968985.

Thaler-Carter, R. (1999). Social Accountability 8000. HR Magazine, 44(6), 106-112. Tsai, S.B., Wu, C.H., Lee, Y. C. \& Lo, K. L. (2011). A Comparison Study on the Evaluation Criteria for Corporate Social Responsibility. International Conference on Management and Service Science (MASS), 12-14 August. 